\title{
Differential Effects of Physical and Chemical Factors on Infectivity of Three Coliphages used as Water Quality Indicator
}

\author{
F.A. Samhan, A.A.Askora*, S.M.Ezzat* and E.I.Abu El- \\ Nil** \\ Water Pollution Control Dept., National Research Center, \\ Cairo; *Botany Department, Faculty of Science, Zagazig \\ University, Zagazig and **Greater Cairo Potable Water \\ Company, Section of Microbiological Examination, the $10^{\text {th }}$ of \\ Ramadan City Laboratory, Egypt.
}

\begin{abstract}
7 HE EFFECT of temperature, $\mathrm{pH}, \mathrm{UV}$, petroleum ether (60-80), acetone (99\%), ethyl alcohol (95\%) and chloroform (99\%) on the infectivity of local coliphage isolates was studied. Three E.coli phages (ECP) were isolated from Ismailia Canal at Mostorod segment. Ability of local E.coli isolates to serve as a host was evaluated after storage at $4-6^{\circ} \mathrm{C}, 25-28^{\circ} \mathrm{C}$ and $35-38^{\circ} \mathrm{C}$ for six months. E.coli isolate number 1 of seven tested served as host for phage reproduction and plaque formation (PF). Phage isolates were identified by plaque size and electron microscopy. ECP1 and ECP2 are Podoviridae and ECP3 is a Siphoviridae. The infectivity of coliphages decreased with increasing storage periods and incubation temperature. Exposure of somatic coliphages to acidic or alkaline $\mathrm{pH}$, organic solvents or UV radiation $(240 \mathrm{~nm})$ or heating $\left(\geq 60^{\circ} \mathrm{C}\right)$ diminished infectivity. Ability of E.coli1 to serve as a host for somatic coliphages inversely related to its age. No detectable effect was found for lower temperature $\leq 5^{\circ} \mathrm{C}$ on the infectivity of coliphage isolates during storage periods.
\end{abstract}

Keywords: Coliphage; Indicator, Water Quality.

Somatic coliphages are viruses that infect E. coli via cell walls (Maniloff \& Ackermann, 1998). With few exceptions, phages in the families Styloviridae, Myoviridae, Podoviridae, and Microviridae comprise the somatic phages (Bradley, 1967 and Snyder, 2012), while phage in the families Leviviridae and Inoviridae are pilus-dependent (Mayo \& Ball, 2006).

Coliphages investigated as possible indicator organisms for human derived strains of viruses since as early as the 1980 (Jamalludeen et al., 2009). They are frequently found in human and animal feces. Some are small, icosahedral and non-enveloped viruses, with protein coat structurally similar to many human enteric viruses (Bertani \& Bertani, 1974). Many similarities between enteric viruses and coliphages regarding environmental transport and survival, however, coliphage survival characteristics vary by season and by group (Ashbolt et al., 2001). Coliphages could replicate inside bacterial hosts also after spilling the 
organic wastes showed higher survival than human associated enteric viruses (Oliveira et al., 2009).

Coliphages are typically detected by the double agar layer with $1 \mathrm{ml}$ test samples (Havelaar \& Hogeboom, 1983). Higher counts have been detected by means of a single-agar-layer method, in this case, four $5 \mathrm{ml}$ fractions of a $20 \mathrm{ml}$ sample were examined (Al-Mola \& Al-Yassari, 2010). The result was used to calculate coliphages count per $100 \mathrm{ml}$. With this method, the minimum detection limit was theoretically calculated as 5 PFU/100 ml (El-Abagy et al., 1988 and Samhan, 2005).

Coliphages similarities to many of human enteric viruses support their fulfillments as indicator of water quality (Beaudoin et al., 2007 and Samhan, 2005). It was concluded that coliphages are a good indication for fecal pollution in a fresh water stream located in an urbanized watershed area (Dini \& De Urraza, 2010 and Samhan, 2005).

Various external physical and chemical factors such as UV (Lee \& Sobsey, 2011 and Nuanualsuwan et al., 2008) temperature, storage temperature and time (Soliman et al., 2013), solvents (Zaritsky et al., 1979 and Rabbani et al., 2004) and $\mathrm{pH}$ (Maillard et al., 1994), the occurrence, viability and infectivity of coliphages (Hachich et al., 2012 and Zaritsky et al., 1979). Protein coat and/or appendages besides lipid loss, and/or DNA structural changes are targets of external factors (Kamolsiripichaiporn et al., 2007 and Soliman et al., 2013).

\section{Materials and Methods}

\section{Bacterial strains}

E. coli ATCC 13079, E. coli ATCC 37022, Staphylococcus aureus ATCC 6538, Klebsiella pneumonia, Enterobacter aerogenes ATCC13048, Salmonella Typhimurium ATCC14028, Staphylococcus aureus ATCC 1298, Pseudomonas aeruginosa ATCC 9027 and Aeromonas hydrophila were used for assaying coliphage isolates to determine its host range.

Isolation and identificationof E. coli

Seven isolates were identified from water samples collected from Ismailia Canal at Mostorad segment, Belbeas, Sharkia, Egypt. The bacterial isolates were purified using M-Endo agar medium and tested with Gram's stain (Cerny, 1976) and preliminary bio-typed using indole test, methyl red test, Voges-Proskauer test, sodium citrate test (IMViC) and oxidase test (Stanek \& Lacy, 1997). The identification was complemented according to APHA (2011) and confirmed serologically with $\mathrm{O}$ group antisera.

\section{Coliphages isolation and purification}

Anti E.coli-active phages were isolated from three sewage samples collected from $10^{\text {th }}$ of Ramadan wastewater treatment plant, Hay El-Zohour and Bahr Elbaker canals at El-Sharkia Governorate. The crudely clarified water sample was

Egypt. J. Microbiol. 51 (2016) 
centrifuged at $4500 \mathrm{rpm}$ for $10 \mathrm{~min}$ at $25^{\circ} \mathrm{C}$ to remove bacterial cells and debris. The supernatant was filtered through $0.45 \mu \mathrm{m}$ (minispart plus) membrane to remove solid particles. Coliphages were identified using $E C 1$ as host for virulent coliphages (Samhan, 2005). The filtrate was mixed with an equal volume of double strength nutrient broth containing fresh $E$. coli 1 cells (final concentration at least $10^{7} \mathrm{CFU} / \mathrm{ml}$ ). After incubation at $37^{\circ} \mathrm{C}$ for at least $12 \mathrm{hr}$, the culture was centrifuged at $4500 \mathrm{rpm}$ for $10 \mathrm{~min}$ and the supernatant was filtered through membrane filter $0.45 \mu \mathrm{m}$. The same E.coli host strain was re-inoculated with the crude phage solution for further multiplication. After incubation at $37^{\circ} \mathrm{C}$ overnight, the cultures were centrifuged at $4500 \mathrm{rpm}$ for $10 \mathrm{~min}$, then a few drops of chloroform were added to avoid microbial contamination and stored at $4^{\circ} \mathrm{C}$. Lytic phage was detected in the filtrate using the double layer method with some modifications(Ghori et al., 2010).

Eight serial dilutions of the phage were performed using saline solution as diluent. The phage were enriched with $0.3 \mathrm{ml}$ of the host culture, $0.1 \mathrm{ml}$ of undiluted enriched phage solution added to a tube containing $3.5 \mathrm{ml} \mathrm{semi-solid}$ agar warmed to $55^{\circ} \mathrm{C}$. The mixture was poured onto a plate of nutrient agar and incubated for $24 \mathrm{~h}$ at $37^{\circ} \mathrm{C}$. The plates were left for 30 min to solidify at room temperature. This procedure was repeated with the $10^{-2}, 10^{-4}, 10^{-6}$ and $10^{-8}$ dilutions to observe plaque formation. The presence of lytic phage in the form of clear plaques was detected after incubation of the plate at $37^{\circ} \mathrm{C}$ overnight (López-Cuevas et al., 2011).

For phage purification as described by Jamalludeen et al. (2009) a single plaque was picked with a sterile glass Pasteur pipette, and transferred to a fresh $E$. coli culture broth. After incubation at $37^{\circ} \mathrm{C}$ overnight, the phage-host mixture was centrifuged at $4500 \mathrm{rpm}$ for $10 \mathrm{~min}$ then filtered through membrane filter $0.45 \mu \mathrm{m}$. The filtrate was assayed with the double layer method as mentioned before. Three rounds repeated of single plaque isolation and re-inoculation was performed. Coliphages were eluted from the final resulting plate by adding $5 \mathrm{ml}$ of phosphate buffer $(\mathrm{pH} 7)$ solution on the top of the plate and incubated at ambient temperature for $4 \mathrm{~h}$ with shaking. The phage-containing buffer retrieved from the plate was centrifuged at $4500 \mathrm{rpm}$ for $10 \mathrm{~min}$ and filtered through a $0.45 \mu \mathrm{m}$ filter (Minispart plus). The resulting filtrate was called phage suspension.

This suspension was used as original stock for single phage isolates. After five successive transfers of single plaques, phage isolates were propagated in plates to give confluent lysis. The collected washes of these plates were treated with chloroform $(0.5 \%)$ to give the phage stocks of high titers (Jensen et al., 1998).

\section{Coliphages titer determination}

The phage containing solution was serially diluted in phosphate buffer ( $\mathrm{pH} 7)$. Double agar layer method was used to assay each dilution. Plaques were counted in the plate containing $0-3 \times 10^{2}$ plaques and counted as plaque forming units per milliliter (PFU/ml) (Rattanachaikunsopon \& Phumkhachorn, 2007).

Egypt. J. Microbiol. 51 (2016) 
Spot test for host specificity

Bacterial isolates and strains were used to test their ability host and propagate coliphage isolates either in low or high titer amount using a spot-test technique (drop method). Stocks of ECP1, ECP2 and ECP3 were obtained by propagation on specific E.coli hosts. Spot tests (Allué-Guardia et al., 2008) were conducted by adding volume of $1 \mathrm{ml}$ of freshly prepared E.coli culture to a tube contained $3.5 \mathrm{ml}$ semi-solid agar medium warmed to $55^{\circ} \mathrm{C}$. Tube contents were poured into a plate of nutrient agar medium. The plates were left to stand at room temperature for $30 \mathrm{~min}$. One drop of phage lysate diluted in phosphate buffer $(\mathrm{pH} 7)$ was spotted by micropipette onto the surface of $E$. coli host lawns. Plates were incubated overnight at $37^{\circ} \mathrm{C}$ and observed for plaque formation. Sensitivity of isolated strains was scored as follows: $\mathrm{CL}=$ confluent lysis and $\mathrm{SCl}=$ semi confluent lysis. Positive plates were recorded and assayed by double layer agar technique (Jensen et al., 1998).

\section{Biological and morphological characterization of isolated phages \\ Electron microscopy investigations}

Morphological assessment of phage isolates was performed by transmission electron microscopy (JEOL $100 \mathrm{cx}$ ) at $80 \mathrm{kv}$ and magnification of 10,000 and 140,000 (Electron Microscope Unit, Faculty of Medicine, Zagazig University). Specimens of each phage were prepared for electron microscopic examination from partially purified phage or $50 \mathrm{ml}$ filtered phage suspension (from confluent lysis plates), which was precipitated at $20,000 \mathrm{rpm}$ of centrifuge at $4^{\circ} \mathrm{C}$ for $24 \mathrm{~h}$. Drops of high-titre filtered phage suspension were laid on formavar coated copper grid (400 meshes) with carbon coated colloidal membrane, which was negatively stained by uranyl acetate $(4 \%$ aqueous). Excess fluids were withdrawn by a filter paper strip(Oliveira et al., 2009). Specimens were washed three times with distilled water, dried on filter paper or air dried and examined by electron microscopy. Size of phage particles was measured directly from negatives using SLP1 ultrastructure size calculator (Samhan, 2005).

\section{Adsorption experiment}

Each filtered lysate of the tested phages (ECP1, ECP2 and ECP3) was added to a $\log$ phase culture of $E C 1$ as an indicator strain at multiplicity of infectivity $=10 \mathrm{PFU} / \mathrm{CFU} / \mathrm{ml}$ (Rattanachaikunsopon \& Phumkhachorn, 2007). Samples of $1 \mathrm{ml}$ were withdrawn and filtered through membrane filters $(0.45 \mu \mathrm{m}$ Millipore $)$ after 4 min intervals and assayed by the double layer technique to determine the titer of non-adsorbed phages (Maillard et al., 1994). Adsorption rate constant was determined by the equation: $\mathrm{K}=(2.3 / \mathrm{BT}) \times \log \left(\mathrm{P}_{\mathrm{o}} / \mathrm{P}\right)$, where $\mathrm{K}$ : adsorption rate constant; B: bacterial host concentration $\left(10^{7} \mathrm{CFU} / \mathrm{ml}\right) ; \mathrm{T}$ : time (min); $\mathrm{P}_{\mathrm{o}}$ : unadsorbed phage concentration at the beginning; $\mathrm{P}$ : unadsorbed phage concentration at the end.

One-step growth curve experiment

Host bacterial strains were infected with phages at multiplicity of infection (MOI) of $0.1 \mathrm{PFU} / \mathrm{CFU} / \mathrm{ml}$ on nutrient broth and incubated at $37^{\circ} \mathrm{C}$. After $60 \mathrm{~min}$, each mixture was centrifuged at $4500 \mathrm{rpm}$ for $10 \mathrm{~min}$. The

Egypt. J. Microbiol. 51 (2016) 
settled cells were suspended in $2 \mathrm{ml}$ nutrient broth followed by dilution one time and counting the bacteria. After 10 min intervals at $37^{\circ} \mathrm{C}$, samples of $0.1 \mathrm{ml}$ were withdrawn and plated onto soft agar with an indicator bacterial strain, serial dilutions were made and plates containing nutrient agar were inoculated. The observed numbers of phages in suspensions were plotted against time and the latent period, rise period and burst sizes were determined (Samhan, 2005 and Yang et al., 2010).

\section{Effect of some physical and chemical factors on the infectivity of phages \\ Incubation temperature}

Two $\mathrm{ml}$ of each phage suspension were incubated at $30^{\circ} \mathrm{C}, 35^{\circ} \mathrm{C}, 40^{\circ} \mathrm{C}, 45^{\circ} \mathrm{C}$, $50^{\circ} \mathrm{C}, 55^{\circ} \mathrm{C}$ and $60^{\circ} \mathrm{C}$ for $10 \mathrm{~min}$ (Srinivasan et al., 2007). Phage infectivity was determined by plaque assay technique (Maillard et al., 1994).

\section{UV irradiation}

Sensitivity to UV irradiation was determined by exposing $10 \mathrm{ml}$ of phage suspension, separately, in a Petri dish directly to UV light at a distance of 15 and $30 \mathrm{~cm}$ from the UV source $(240 \mathrm{~nm})$. A 30-Watt general electric lamp was used as UV source. All manipulations were made in the dark to avoid photoreaction (Lee \& Sobsey, 2011). Samples of phage suspensions were exposed separately to UV irradiation for different time periods $(30,60,90$, . and $180 \mathrm{~min})$. Phage infectivity was determined by plaque assay technique (Nuanualsuwan et al., 2008).

\section{Different organic solvents}

Two ml of different organic solvents (petroleum ether (60-80), acetone (99\%), ethyl alcohol (95\%) and chloroform (99\%)) was added to $2 \mathrm{ml}$ of phage suspension. After $30 \mathrm{~min}$ in shaking incubator, the phage suspension was centrifuged at $4500 \mathrm{rpm}$ for $10 \mathrm{~min}$ and $30^{\circ} \mathrm{C}$. Twenty $\mu \mathrm{l}$ were diluted to $5 \mathrm{ml}$ to stop the effect of chloroform and assayed for the infectivity of phages by plaque assay (Maillard et al., 1994).

\section{$p H$ values}

A one $\mathrm{ml}$ portion of each phage suspension was transferred into test tubes containing $9 \mathrm{ml}$ of nutrient broth. The $\mathrm{pH}$ of the total suspension was adjusted at various values from 4 to 10 . The $\mathrm{pH}$ values of nutrient broth was adjusted using $1 \mathrm{~N} \mathrm{KOH}$ and/or HCl (Srinivasan et al., 2007). After an hour of incubation at $30^{\circ} \mathrm{C}$ the infectivity of phages was determined by carrying out double layer technique (Maillard et al., 1994).

\section{Different storage temperature}

Phage suspensions of high-titer lysates were incubated at $4-6^{\circ} \mathrm{C}, 25-28^{\circ} \mathrm{C}$ and $35-37^{\circ} \mathrm{C}$ separately for six months (Nuanualsuwan et al., 2008). The infectivity of phages was assayed weekly by carrying out double layer technique (Maillard et al., 1994). 


\section{Results}

Isolation and identification of local E. coli isolates

Seven local isolates of $E$. coli 1 to 7 were isolated from raw water. The isolates were presumptively tested and confirmed by acid and gas production on EC broth tubes as a result of lactose fermentation. From each positive EC tube an inoculum was streaked on M-Endo agar plates, the colonies were green with metallic sheen considered as fecal coliforms. The isolates were Gram negative, non-spore former, rod shaped bacteria, grow on and ferment lactose with gas production at $44.5 \pm 0.5^{\circ} \mathrm{C}$, positive indole test, positive methyl red test, negative Voges-Proskauer test, negative sodium citrate test and negative oxidase test. All isolates were Gram s negative.

\section{Sensitivity of E. coli isolates}

After dropping ECP1, ECP2 and ECP3 lysates diluents onto the surface of freshly prepared $E$. coli host lawns spread on nutrient agar plates lytic zones or plaques were only when $E$. coli isolate 1 was the host. On the other hand, plaques were not observed when E. coli 2, E. coli 3, E. coli 4 , E. coli 5 , E. coli 6 and E. coli 7 were used to host phage isolates. In parallel, the three phages isolates showed clear plaques using the double layer method and E. coli 1 as a host, indicating a lytic or virulent phage. Taking into account the shape and the size of the plaques three types of phages termed ECP1, ECP2 and ECP3 were identified.

\section{Morphological characterization of phages isolates}

Plaques morphology

The plaques appearance of the three phage isolates ECP1, ECP2 and ECP3 were clear but variable in size. After $24 \mathrm{~h}$ incubation at $37^{\circ} \mathrm{C}$, the diameter of $\mathrm{ECP} 1$ plaque had size varying from 1 to $2 \mathrm{~mm}$, the diameter of ECP2 plaques varied from 1.5 to $2.5 \mathrm{~mm}$ and ECP3 diameter varied from 3 to $5 \mathrm{~mm}$.

\section{Electron microscopy studies}

Examination of purified ECP1, ECP2 and ECP3 particles showed morphologies typical of double stranded DNA bacteriophages. ECP1and ECP2 had cubic (icosahedral), short non-contractile tail with capsids up to $65 \mathrm{~nm}$ typical of members of linear dsDNA T7 phage and Enterobacter phage P22 (Fig.1). ECP3 had cubic (icosahedral) capsid, capsids up to $60 \mathrm{~nm}$ with a long non-contractile tail suggesting, it may linear dsDNAphages like $\mathrm{T} 5$ and $\mathrm{Tl}$ or $\lambda$ (E. coli) B 40-8 (Bacteroides fragilis). Therefore, ECP1 and ECP2 phages were classified as group Podoviridae family and ECP3 phage was classified as group Siphoviridae family (Fig.1).

\section{Biological characterization of phages isolates \\ Effect of the host age on the infectivity of phages}

The infectivity of the phages isolates ECP1, ECP2 and ECP3 decreased with the increase of the host age. The infectivity of ECP2 and ECP3 was more sensitive to the age longevity of the E. coli 1; infectivity was recorded as $38.7 \%$ and $25.6 \%$, respectively, after $96 \mathrm{~h}$. On the contrast, ECP1 was the most resistant to host age, where the infectivity reached $55.3 \%$ after $96 \mathrm{~h}$. 


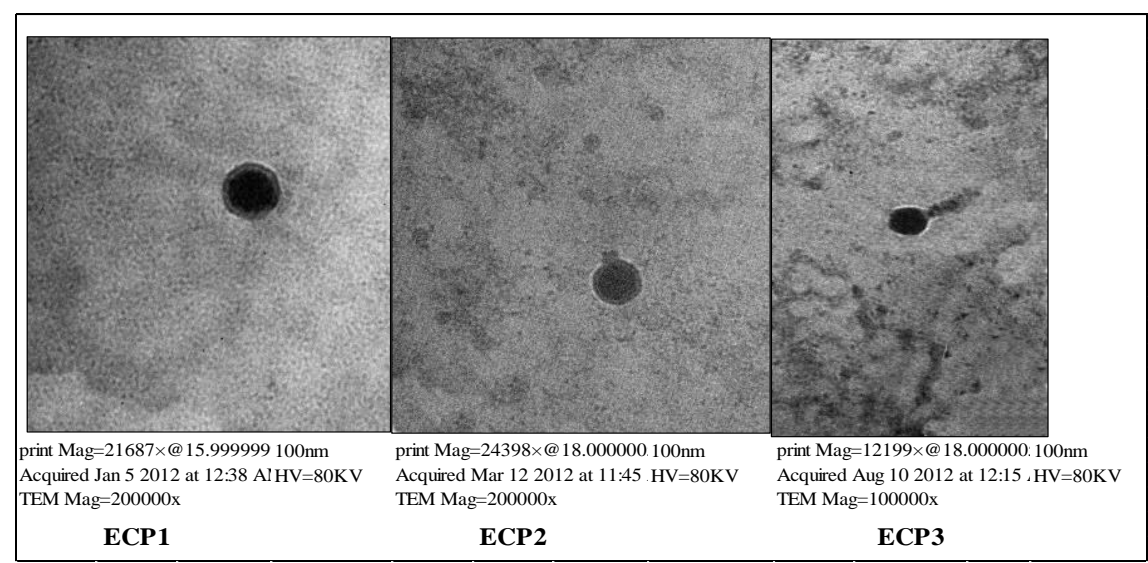

Fig. 1. Transmission electron microscopy images of phages: ECP1 and ECP2 had cubic (icosahedral) capsid, short non-contractile tail; ECP3 had cubic (icosahedral) capsid, long non-contractile tail.

\section{Host range}

After exposing sixteen bacterial isolates and strains to determine the host range of each of the phage isolates lytic areas were observed only when ECP1, ECP2 and ECP3 were spotted on E. coli 1 and reference strain E. coli ATCC 13079 lawns. But none of the other 6 isolates or strains showed lytic areas.

\section{Adsorption experiment}

ECP1, ECP2 and ECP3 exhibited different adsorption rates (Fig. 2 and Table 1). Where ECP3 had the lowest adsorption constant $1.90 \times 10^{-6} \mathrm{PFU} / \mathrm{CFU} / \mathrm{ml}$, ECP2 and ECP1had rate of adsorption constants $3.23 \times 10^{-6} \mathrm{PFU} / \mathrm{CFU} / \mathrm{ml}$ and $3.24 \times 10^{-6} \mathrm{PFU} / \mathrm{CFU} / \mathrm{ml}$, respectively. All phage isolates had $32 \mathrm{~min}$ time for maximum adsorption. Adsorption was calculated as $76 \%, 63.5 \%$ and $62.5 \%$ for ECP3, ECP2 and ECP1, respectively within 20 min after contact.

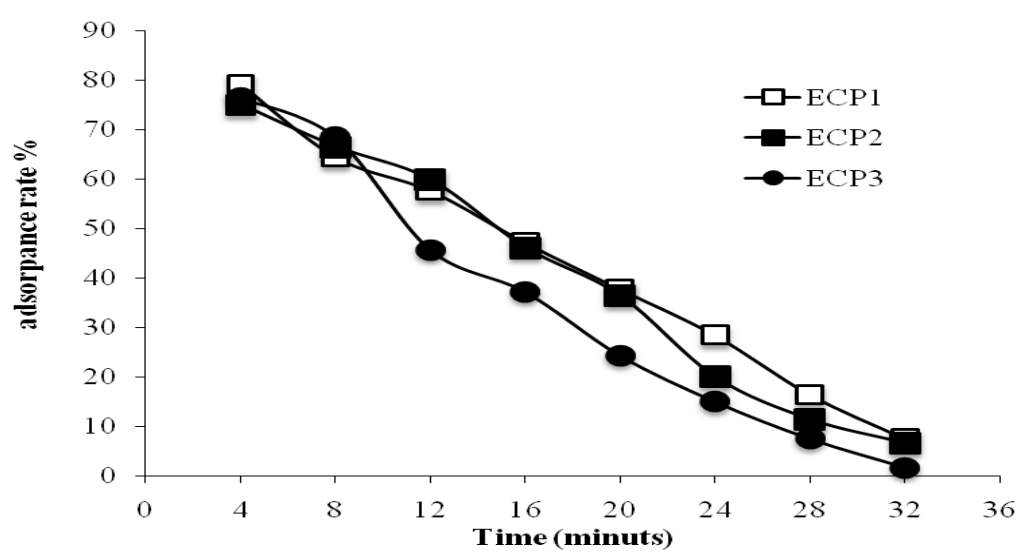

Fig. 2. Adsorption rates of phage isolates. 
TABLE 1. Growth characteristics of phage isolates.

\begin{tabular}{|l|c|c|c|}
\hline Phage character & ECP1 & ECP2 & ECP3 \\
\hline Time for maximum adsorption (minutes) & 32 & 32 & 32 \\
\hline Adsorption rate constant (PFU/CFU/mL) $\times 10^{-6}$ & 3.24 & 3.23 & 1.90 \\
\hline Latent period (minutes) & 20 & 20 & 20 \\
\hline Rise period (minutes) & 40 & 40 & 40 \\
\hline Burst size (PFU/cell) & 70.1 & 40.3 & 79.4 \\
\hline
\end{tabular}

One-step growth curve

ECP1, ECP2 and ECP3 had almost identical latent periods of $20 \mathrm{~min}$; during this period phage titer was nearly stable (Fig. 3). After latent period, the titer of the phages increased to the maximum value during the rise period. Also, the three isolated phages had almost identical rise period $40 \mathrm{~min}$. The burst size indicates the mean number of viral progeny released per infected bacterial cell. The burst sizes of ECP1, ECP2 and ECP3 were 70.1, 40.3 and 79.4 PFU/cell, respectively.

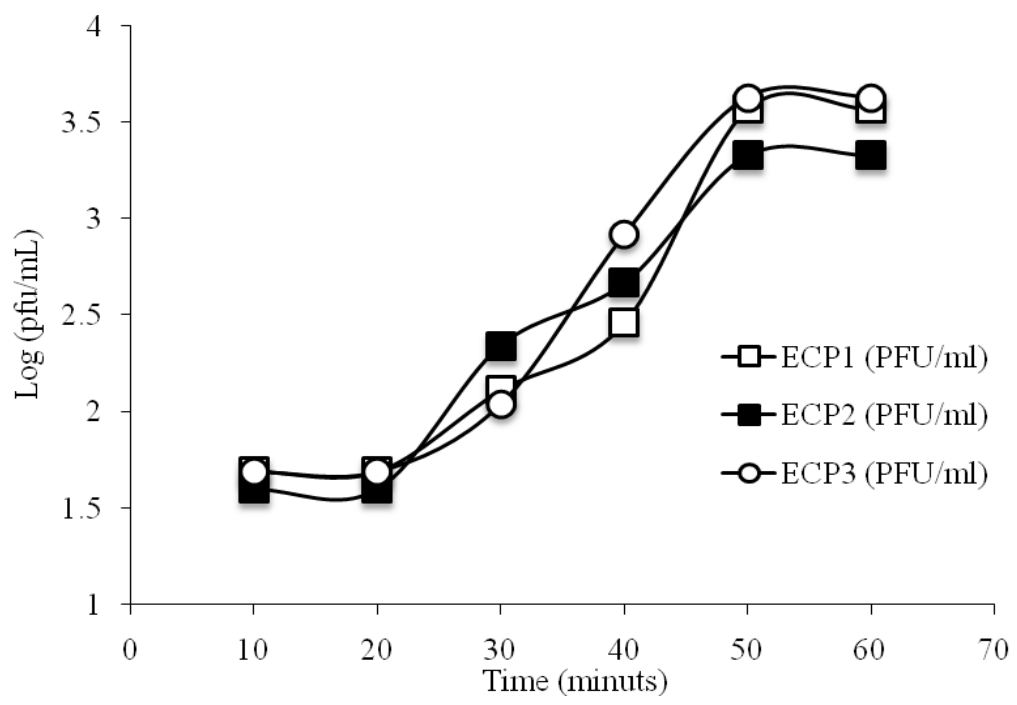

Fig. 3. One-step growth curves of coliphage isolates.

Characterization of isolated phages in response to physical treatments

Effect of temperature on the infectivity of isolated phages

ECP1, ECP2 and ECP3 were highly sensitive to heat inactivation. Active phages were not detected after exposure to $60^{\circ} \mathrm{C}$ for $10 \mathrm{~min}$. The highest number of plaques formed was observed after heated at $30^{\circ} \mathrm{C}$, survival percentage reached $92.7,88.2$ and 94.3 for ECP1, ECP2 and ECP3, respectively. The viability decreased with the increase of the temperature degrees (Fig. 4). 


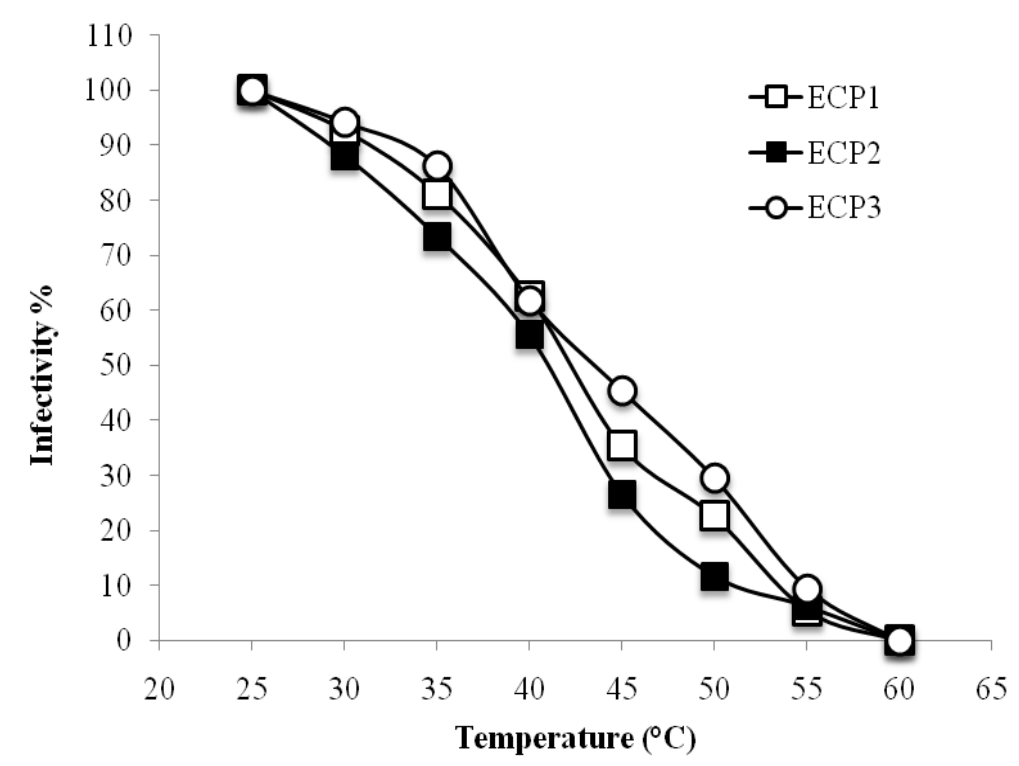

Fig. 4. Effect of $10 \mathrm{~min}$ heating on the infectivity of coliphage isolates.

Effect of $U V$-irradiation on the infectivity of phage isolates

The exposure of ECP1, ECP2 and ECP3 to UV-radiation showed inhibitory effects on infectivity. At $15 \mathrm{~cm}$ from the UV source, $180 \mathrm{~min}$ exposure was sufficient for complete inactivation of ECP1. ECP2 was completely inactivated after 150 min exposure time. ECP3 was the most sensitive for UV-irradiation than ECP1 and ECP2; it was completely inactivated after 110 min with standard error 12.8, 6.5 and 14.6 for ECP1, ECP2 and ECP3, respectively. At $30 \mathrm{~cm}$ distance UV-irradiation for $180 \mathrm{~min}$ of exposure achieved 74.4, 76.1 and $87.4 \%$ of inactivation for ECP1, ECP2 and ECP3 with standard error 9.9, 5.9 and 6.9, respectively. No change in plaque morphology was observed after UV irradiation under the studied conditions.

Effect of organic solvents on the infectivity of phage isolates

Incubating phage suspensions with petroleum ether, acetone, ethyl alcohol and chloroformin ratio $1: 1(\mathrm{v} / \mathrm{v})$ for $30 \mathrm{~min}$ at $37^{\circ} \mathrm{C}$ reduced its infectivity. Chloroform was the most effective solvent that reduced the infectivity of ECP1, ECP2 and ECP3 to $35.4 \%, 32.6 \%$ and $45.8 \%$, respectively. On the other hand, petroleum ether showed the lowest inhibiting effect on the infectivity of ECP1, ECP2 and ECP3, it was reduced to $92.9 \%, 83.5 \%$ and $93.9 \%$, respectively. ECP2 was the most sensitive one for solvents. In contrast, the infectivity of ECP3 was slightly affected by solvents. Moreover, data showed that the infectivity of all phages was still above $30 \%$ after incubation for $30 \mathrm{~min}$ with each of the tested organic solvents (Fig. 5). 


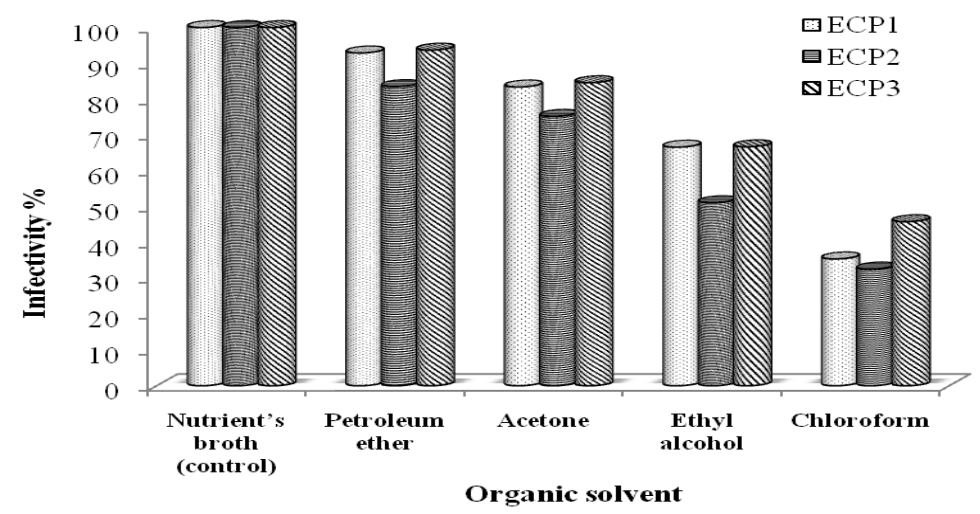

Fig. 5. Effect of organic solvents on the infectivity of coliphage isolates.

Effect of $\mathrm{pH}$ values on the infectivity of phage isolates

The optimum $\mathrm{pH}$ values for the three phages were determined by incubation of phage suspensions at $\mathrm{pH}$ values ranging from 4 to 10 for $30 \mathrm{~min}$ at $30^{\circ} \mathrm{C}$. The phages particles were determined by double layer technique. The $\mathrm{pH} 6$ was optimum for stability. The infectivity of the three phages rapidly decreased towards alkalinity compared to $\mathrm{pH}$ 6. Moreover, plaque formation of ECP2 was more sensitive to $\mathrm{pH}$ exchange than ECP1 and ECP3 (Fig. 6). ECP1, ECP2 and ECP3 have showed standard error 2.25, 2.23 and 2.23, respectively.

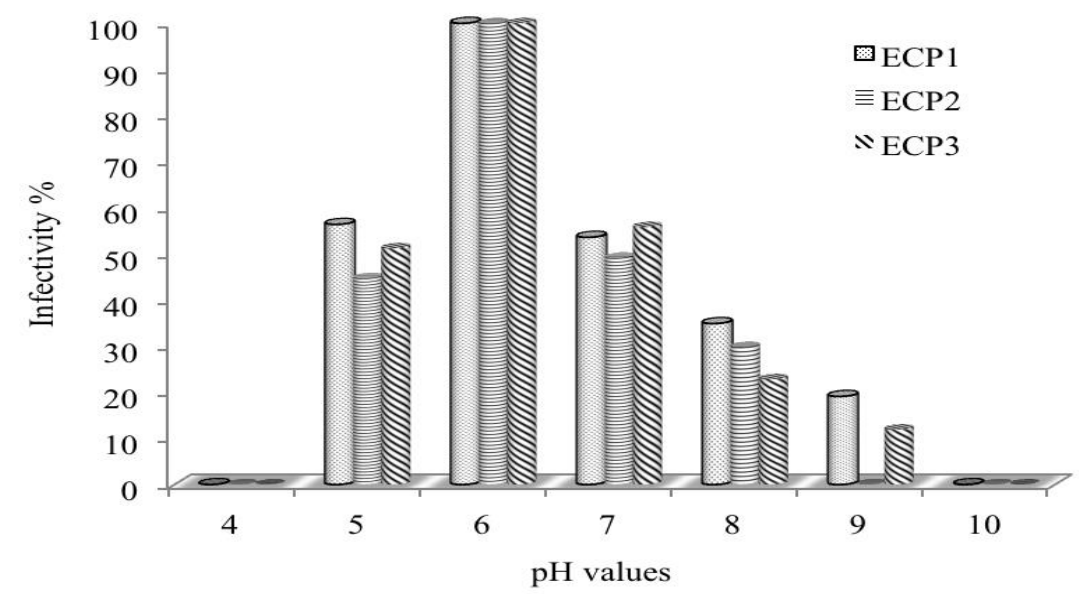

Fig. 6. Effect of $\mathrm{pH}$ values on the infectivity of coliphage isolates.

Effect of different storage temperatures on phages infectivity

The storage of ECP1, ECP2 and ECP3 at $35-37^{\circ} \mathrm{C}$ and $3-5^{\circ} \mathrm{C}$ showed the least effect on its infectivity after extended incubation for one to five weeks. The ability of phages to form plaques after different storage temperatures was slightly

Egypt. J. Microbiol. 51 (2016) 
affected. Phage counts decreased by nearly $50 \%$ after 5 weeks. The results showed standard error at the two incubation temperature 0.09 and 0.15 , respectively.

\section{Discussion}

Somatic coliphages are considered as a suitable indicators for the presence of enteric calve bovine viruses in fresh water, raw and partially treated wastewater and liquid organic wastes (Samhan, 2005), in addition, it reflects the presence of E.coli. Some authors proposed the use of E. coli beside somatic coliphages. Both together satisfy most criteria for an ideal indicator for the presence of more difficult to screen species (López-Cuevas et al., 2011) and could be more informative than using two bacterial indicators (Lucena et al., 2003).

Plaque morphology is essential criteria for detection, identification and classification of phages. Normally, phages exhibit well-defined plaque characteristics, including size, outline, structure and transparency or turbidity (El-Abagy et al., 1988 and Samhan, 2005). After $24 \mathrm{~h}$ of incubation at $37^{\circ} \mathrm{C}$, coliphage isolates were differentiated into three types according to their morphology. All of them were clear but plaque diameters varied in size, the diameter of ECP1 plaque had size from 1 to $2 \mathrm{~mm}$, while the diameter of ECP2 plaques was from 1.5 to $2.5 \mathrm{~mm}$ and ECP3 diameter was from 3 to $5 \mathrm{~mm}$. The obtained results tentatively assign the isolated phages to the Caudovirales order of the Myoviridae family, consistent with the morphotypes of A1 (Bo-21) and A2 (Av-05, Av-06 and Av-08) (Srinivasan et al., 2007). Almost all of the phages isolated from mammalian feces have been to Myoviridae family and are associated with the lytic effect in E.coli (Yang et al., 2010). In another study, six lytic bacteriophages which infected enterotoxigenic E.coli strains produced similar plaques that were clear and medium-sized, ranging from 1.5 to $3.5 \mathrm{~mm}$ in diameter (Snyder, 2012). On the other hand, electron microscopic examination showed that both phages ECP1 and ECP2 were classified as members belonging to the Podoviridae family and phage ECP3 classified as member belonging to the Siphoviridae family. According to Bradley (1967) and Snyder (2012) classification of ECP1and ECP2 had cubic (icosahedral) capsid, linear dsDNA, capsids up to $65 \mathrm{~nm}$ and both two phages had short non-contractile tails. ECP3 had cubic (icosahedral) capsid, linear dsDNA, long non-contractile tail, capsids up to $60 \mathrm{~nm}$ (Snyder, 2012). Myoviridaeare characterized by those having icosahedral or elongated heads and contractile tails that are more or less rigid, long, and relatively thick. This proposed identification agreed with the international committee on the taxonomy of viruses (ICTV) (Mayo \& Ball, 2006).

The infectivity of the coliphage isolates ECP1, ECP2 and ECP3 decreased with the increase of the host age (Chan et al., 2004). The infectivity of ECP2 and ECP3 phages were more sensitive to the age of the host, their infectivity reduced to $38.7 \%$ and $25.6 \%$, respectively, after $96 \mathrm{~h}$. ECP1 was the most resistant to the host age where its infectivity reached $55.3 \%$ after $96 \mathrm{~h}$ of incubation. This might be attributed to the time required for the changes in polysaccharides constituting the receptive 
points scattered on the host cell wall (Ashbolt et al., 2001 and Samhan, 2005). During the stationary phase, E. coli specifically up-regulates the expression of specific proteins and down-regulates others. These physiological and genetic changes have a dramatic effect on the susceptibility of E.coli to coliphage infection. These results agree with previous studies (Stanek \& Lacy, 1997). The age of the overnight culture was tested to determine if the age of the culture used to inoculate the subcultures would affect the assay results. As little as $8 \mathrm{~h}$ were required to yield sufficient cell count to provide an adequate inoculum for the assay. In addition, an overnight up to $41 \mathrm{~h}$ old still functioned well in the assay.

The host range results revealed that ECP1, ECP2 and ECP3 exhibited specificity to E.coli1. Since adsorption to the host cell is controlled by molecular interactions between the phage tail fibers and the cell surface only this strain has appropriate binding site. Where host range is determined by the orientation of the $\mathrm{G}$ segment in the phage, in our case the results show that the $\mathrm{G}$ segment is in the $\mathrm{G}$ positive orientation, allowing it to infect E.coli specific host only. Consequently, lytic areas were observed only when ECP1, ECP2 and ECP3 were spotted on local E.coli1 isolates and E. coli ATCC 13079 (El-Abagy et al., 1988). In contrast, if the $\mathrm{G}$ segment is in the negative orientation, the phage will infect E.coli and several other species of enteric bacteria. This was demonstrated in previous studies(López-Cuevas et al., 2011), who showed that four isolate phages had a broad host range. Further characterization showed isolate Bo-21 was lytic against 192 of 234 tested strains including Salmonella serotypes and E. coli $\mathrm{O} 157: \mathrm{H7}$. On the other hand, no plaques were formed in case of enteropathogenic and enterotoxigenic E.coli assayed as host (Wang \& Lin, 2001). The differences in bacteriophages host range may be associated with diminishing adsorption to an acceptable bacterial receptor. Both evasion systems can be seen in Salmonella or E. coli serotypes (Snyder, 2012).

Coliphage isolates exhibited different adsorption constants (Table 1 and Fig. 2), where ECP3 had the lowest constant, $1.90 \times 10^{-6} \mathrm{PFU} / \mathrm{CFU} / \mathrm{ml}$, followed by ECP2 with adsorption constant value of $3.23 \times 10^{-6} \mathrm{PFU} / \mathrm{CFU} / \mathrm{ml}$ then ECP1 with adsorption constant $3.24 \times 10^{-6} \mathrm{PFU} / \mathrm{CFU} / \mathrm{ml}$. All coliphage isolates had the same time requirement for maximum adsorption (32 min). About $76 \%, 63.5 \%$ and $62.5 \%$ of the infective ECP3, ECP2 and ECP1 particles, respectively were adsorbed to the cells of E.coli host within $20 \mathrm{~min}$ after contact. Similarly LópezCuevas et al.(2011) and Wang \& Lin (2001) showed that adsorption is the first event of the infection process which has been divided into two stages. The rate of $\mathrm{T} 4$ adsorption per unit surface area was calculated according to an experimental equation(Al-Mola \& Al-Yassari, 2010), derived from the known dimensions of the same sub strain $\mathrm{H} 266$ of $E$. coli and found to be constant.

ECP1, ECP2 and ECP3 had almost identical latent period 20 min, after which the titer of the phages increased until reached the maximum value during the rise period. Also, the three coliphage isolates had almost identical rise periods of $40 \mathrm{~min}$. The burst size indicates the mean number of viral

Egypt. J. Microbiol. 51 (2016) 
progeny released per infected bacterial cell. The burst sizes of ECP1, ECP2 and ECP3were 70.1, 40.3 and 79.4 PFU/cell, respectively.

Thermal inactivation pattern of phage isolates ECP1, ECP2 and ECP3 were highly sensitive to elevated temperature and the numbers of plaques were greatly reduced. After just $10 \mathrm{~min}$, increasing temperature reduced the numbers of congruent plaques on indicator strain E.coli1 (Kamolsiripichaiporn et al., 2007). The coliphage isolates were inactivated after exposure to $60^{\circ} \mathrm{C}$ for 10 min. The optimal temperature was $30^{\circ} \mathrm{C}$, plaque formation reaching $92.7,88.2$ and 94.3 for the three coliphages isolates, respectively. The infectivity of the three isolates was decreased with increasing the temperature. Heat treatments at $57^{\circ} \mathrm{C}$ and $77^{\circ} \mathrm{C}$ for period of $15 \mathrm{~min}$ or longer time inactivated the virus. Heating the virus suspension at $56^{\circ} \mathrm{C}$ for 60 min reduced its infectivity (Kamolsiripichaiporn et al., 2007). High temperature degrees might be responsible for destruction of virus receptors that consequently declined its infectivity. Al-Mola \& Al-Yassari (2010) found that number of plaques and phage titers during $10,20,30,40,50$, and $60 \mathrm{~min}$ were $4.7 \times 10^{-5}, 5.3 \times 10^{-5}$, $6.0 \times 10^{-5}, 8.5 \times 10^{-5}, 8.9 \times 10^{-5}$ and $9.3 \times 10^{-5}$, respectively; at $37^{\circ} \mathrm{C}$. Phage titers were $6.2 \times 10^{-5}, 5.6 \times 10^{-5}, 4.1 \times 10^{-5}, 3.6 \times 10^{-5}, 2.0 \times 10^{-5}$ and $1.6 \times 10^{-5}$, respectively; at $50^{\circ} \mathrm{C}$. The phage titers were $0.9 \times 10^{-5}, 0.1 \times 10^{-5}, 0,0,0$ and 0 ), respectively; at $65^{\circ} \mathrm{C}$ (Allué-Guardia et al., 2012 and Snyder, 2012).

The infectivity of the phage isolates gradually decreased with increasing time and decreasing distance of exposure to UV-irradiation until complete inhibition took place. At $15 \mathrm{~cm}$ distance from the UV source, $180 \mathrm{~min}$ of exposure was sufficient for complete inactivation of phages. ECP2 was inactivated completely after $150 \mathrm{~min}$. So, ECP3 was more sensitive to UVirradiation than ECP1 and ECP2. At $30 \mathrm{~cm}$ distance from the UV source, exposure for $180 \mathrm{~min}$ was not sufficient for complete inactivation of phages ECP1, ECP2 or ECP3 (Nuanualsuwan et al., 2008). It was found that $74.4 \%$, $76.1 \%$ and $87.4 \%$ inactivation were observed after $180 \mathrm{~min}$ of exposure of $\mathrm{UV}$-irradiation for ECP1, ECP2 and ECP3, respectively. The inactivation of the tested phages might be attributed to modifications or actual breaks in DNA or disruption of DNA and death of the exposed phages (Allué-Guardia et al., 2012; Jończyk et al., 2011 and Nuanualsuwan et al., 2008). No change in plaque morphology was observed after UV irradiation under the studied conditions. Ghori et al.(2010) showed that the virus exposed to UV light was not inactivated after interaction time of 15, 30 and $45 \mathrm{~min}$. In addition, the presence of bovine serum albumen helped the corona virus to survive the UV treatment.

Regarding the effect of organic solvents on the infectivity of coliphage isolates, chloroform was the most effective solvent, likely because it causes contraction of the tail during attachment to be reversible (Zaritsky et al., 1979 and Rabbani et al., 2004). ECP1, ECP2 and ECP3 infectivity decreased to $35.4 \%, 32.6 \%$ and $45.8 \%$, respectively. On the other hand, petroleum ether had the lowest inhibition effect on the infectivity of coliphage isolates calculated as 
$92.9 \%, 83.5 \%$ and $93.9 \%$, respectively. ECP2 was the most sensitive to inactivation by solvents. By contrast, infectivity of phage ECP3 was slightly affected by solvents. Others have reported that coliphage were completely inactivated by chloroform treatment (Al-Mola \& Al-Yassari, 2010). Bertani \& Bertani (1974) reported that some phages contain lipids in virions and these lipids are essential for maintaining virus ability to infect new host cells. Nonpolar solvents are capable of denaturing proteins by disrupting the hydrophobic interaction between proteins, which is part of phage viability (Bertani \& Bertani, 1974). The present work showed that all tested organic solvents inactivated phages to different percentages at certain conditions support the previous findings for Wang \& Lin (2001).

Regarding the stability at different $\mathrm{pH}$ values, the three coliphage isolates were very sensitive to changes in the hydrogen ions concentration. The viability of the tested phages more rapidly decreased towards alkalinity compared to acidity (Ghori et al., 2010). At pH 10, plaques formation was not observed for ECP1 and ECP3 while at $\mathrm{pH}$ 9, plaques formation was not observed for ECP2. While, the percentages of survivors at $\mathrm{pH} 5$ were $56 \%$ $44 \%$ and $51 \%$ for ECP1, ECP2 and ECP3, respectively compared to counts at $\mathrm{pH} 6$, at $\mathrm{pH} 7, \mathrm{pH} 8$ or $\mathrm{pH} 9$, the respective percentage of survivors reached 53 , 34 and 19\% for ECP1; 49, 29 and 0\% for ECP2; 55, 22 and 1\% for ECP3, respectively. Our results had agreement with Jamalludeen et al. (2009) who reported that bacteriophages are often quite sensitive to protein denaturation in an acidic environment which leads to loss of bacteriophages viability. This was defined as phage sensitivity to protein denaturation in an acidic environment (Jamalludeen et al., 2009; Oliveira et al., 2009 and Clermont et al., 2011). Presumably, the viral capsid is hydrolyzed or dissociated at low $\mathrm{pH}$ (Maillard et al., 1994). On the other hand, phages were stable and survive at close to neutral $\mathrm{pH}$ values between 5 and 9 . Many authors reported that most phages are able to survive well over a wide range of $\mathrm{pH}$ at physiological conditions that maintain the native virion structure and stability (Bertani \& Bertani, 1974).

The abilities of phage isolates to form plaques after different storage periods were inversely proportioned to incubation temperature. The infectivity processes or propagation cycles were not properly completed, reflecting a decrease in the total viability of phages. Number of plaques formed by ECP1, ECP2 and ECP3 after the first week incubation at $3-5^{\circ} \mathrm{C}$ were decreased to $54.6 \%, 55.5 \%$ and $53.4 \%$, respectively, while at $25-28^{\circ} \mathrm{C}$ plaque counts decreased to $35.8 \%, 43.8 \%$ and $45.9 \%$, respectively after second week. On the other side, after the third week, the Plaque counts at $35-37^{\circ} \mathrm{C}$ were reduced to $14.6 \%, 16.3 \%$ and $12.4 \%$, respectively. Similar results (Jamalludeen et al., 2009) had agreement that E. coli phage viability decreased in its count by about half a $\log / \mathrm{ml}$ every ten days.

It is well established that viruses are more resistant than $E$. coli to a variety of environmental stresses and water treatment processes, consequently it

Egypt. J. Microbiol. 51 (2016) 
persists longer in aquatic environments than do bacteria (Samhan, 2005). In this study, coliforms (total and fecal) were not detected in the presence of coliphages in the 40 potable water samples.

\section{Conclusion}

Exposure of somatic coliphage isolates for chemical conditions; acidic or alkaline $\mathrm{pH}$, organic solvents or physical conditions; UV radiation $(240 \mathrm{~nm})$ or heating $\left(\geq 60^{\circ}\right.$ C) could diminish its E.coli specific host infectivity consequently indication for E.coli presence in water. E.coli viability as a host for somatic coliphages inversely related to its age. Lower temperature $\leq 5^{\circ} \mathrm{C}$ has the least inhibition effect on the infectivity of coliphage isolates during storage periods.

\section{References}

Al-Mola, G. A. and Al-Yassari, I. H. (2010) Characterization of E.coli phage isolated from sewage. AL-Qadisiya Journal of Vet. Med. Sci. 9(2), 45-52.

Allué-Guardia, A., Jofre, J. and Muniesa, M. (2012) Stability and infectivity of cytolethal distending toxin type $\mathrm{V}$ gene-carrying bacteriophages in a water mesocosm and under different inactivation conditions. Applied and Environmental Microbiology, 78(16), 5818-5823.

American Public Health Association (APHA) (2012) Standard Methods for the Examination of Water and Wastewater, Differentiation of coliform bacteria 9225 B. Culture purification $9225 \mathrm{C}$, The $22^{\text {nd }}$ ed.

Ashbolt, N., Grabow, W. and Snozzi, M. (2001) Indicators of microbial water quality. "Water Quality: Guidelines, Standards and Health," (Grabow 1996),pp. 289-316.

Beaudoin, R. N., Decesaro, D. R., Durkee, D. L. and Barbaro, S. E. (2007) Isolation of a bacteriophage from sewage sludge and characterization of its bacterial host cell. River Academic Journal, 3(1), 1-8.

Bertani, G. and Bertani, L. E. (1974) Constitutive expression of bacteriophage P2 early genes resulting from a tandem duplication. Proc. Natl. Acad. Sci. U S A, 71(2), 315319.

Bradley, D.E. (1967) Ultrastructure of bacteriophages and bacteriocins, Bacteriol. Rev. 31(4), 230-314.

Cerny, G. (1976) Method for the distinction of gramnegative from grampositive bacteria. European Journal of Applied Microbiology, 3(3), 223-225.

Chan, C., Chan, J., Lee, G. and Lee, J. (2004) Culture age and axtrinsic factors affect formation of T4 bacteriophage infective centers in stationary phase Escherichia coli ZK126. Journal of Experimental Microbiology and Immunology, 5, 50-60.

Clermont, O., Olier, M., Hoede, C., Diancourt, L., Brisse, S., Keroudean, M., Glodt, J., Picard, B., Oswald, E. and Denamur, E. ( 2011) Animal and human pathogenic Egypt. J. Microbiol. 51 (2016) 
Escherichia coli strains share common genetic backgrounds. Infect. Genet. Evol. 11, 654-662.

Dini, C. and De Urraza, P. J. (2010) Isolation and selection of coliphages as potential biocontrol agents of enterohemorrhagic and Shiga toxin-producing E. coli (EHEC and STEC) in cattle. Journal of Applied Microbiology, 109(3), 873-887.

El-Abagy, M. M., Dutka, B. J., Kamel, M. and el Zanfaly, H. T. (1988) Incidence of coliphage in potable water supplies. Applied and Environmental Microbiology, 54(6), $1632-3$.

Hachich, E. M., Di Bari, M., Christ, A. P. G., Lamparelli, C. C., Ramos, S. S. and Sato, M. I. Z. (2012) Comparison of thermotolerant coliforms and Escherichia coli densities in freshwater bodies. Brazilian Journal of Microbiology, 43(2), 675-81.

Havelaar, H. and Hogeboom, W. M. (1983) Factors affecting the enumeration of coliphages in sewage and sewage-polluted waters. Antonie van Leeuwenhoek, 49(45), 387-397.

Ghori, M.T., Muhammad, K. and Rabbani, M. A. (2010) Physical factors affecting in vitro replication of foot and mouth disease virus (serotype "O"), Pakistan Veterinary Journal, 31 (4), 313-316.

Jamalludeen, N., She, Y.-M., Lingohr, E. J. and Griffiths, M. (2009) Isolation and characterization of virulent bacteriophages against Escherichia coli serogroups O1, O2, and O78. Poultry Science, 88(8), 1694-1702.

Jensen, E. C., Schrader, H. S., Rieland, B., Thompson, T. L., Lee, K. W., Nickerson, K. W. and Kokjohn, T. (1998) Prevalence of broad-host-range lytic bacteriophages of Sphaerotilus natans, Escherichia coli, and Pseudomonas aeruginosa. Applied and Environmental Microbiology, 64(2), 575-580.

Jończyk, E., Kłak, M., Międzybrodzki, R. and Górski, A. (2011) The influence of external factors on bacteriophages — review. Folia Microbiologica, 56(3), 191-200.

Kamolsiripichaiporn, S., Subharat, S., Udon, R., Thongtha, P. and Nuanualsuwan, S. (2007) Thermal inactivation of foot-and-mouth disease viruses in suspension. Applied and Environmental Microbiology, 73(22), 7177-84.

Lee, H. S. and Sobsey, M. D. (2011) Survival of prototype strains of somatic coliphage families in environmental waters and when exposed to UV low-pressure monochromatic radiation or heat. Water Research, 45(12), 3723-34.

López-Cuevas, O., Castro-del Campo, N., León-Félix, J., González-Robles, A. and Chaidez, C. (2011) Characterization of bacteriophages with a lytic effect on various Salmonella serotypes and Escherichia coli O157:H7. Canadian Journal of Microbiology, 57(12), 1042-1051.

Lucena, F., Méndez, X., Morón, A., Calderón, E., Campos, C., Guerrero, A. and Jofre, J. (2003) Occurrence and densities of bacteriophages proposed as indicators and bacterial indicators in river waters from Europe and South America. Journal of Applied Microbiology, 94(5), 808-815.

Egypt. J. Microbiol. 51 (2016) 
Maillard, J. Y., Beggs, T. S., Day, M. J., Hudson, R. and Russell, D. (1994) Effect of Biocides on MS2 and K Coliphages. Applied and Environmental Microbiology, 60(6), 2205-6.

Maniloff, J. and Ackermann, H.W. (1998) Taxonomy of bacterial viruses: Establishment of tailed virus genera and the order Caudovirales. Archives of Virology, 143(10), 2051-2063.

Mayo, M. A. and Ball, L. A. (2006) ICTV in San Francisco: A report from the Plenary Session. Archives of Virology, 151(2), 413-422.

McLaughlin, M. R. and Balaa, M. F. (2006) Enhanced contrast of bacteriophage plaques in Salmonella with ferric ammonium citrate and sodium thiosulfate (FACST) and tetrazolium red (TZR). Journal of Microbiological Methods, 65(2), 318-323.

McLaughlin, M.R. and King, R. A. (2008) Characterization of Salmonella bacteriophages isolated from swine lagoon effluent. Current Microbiology, 56(3), 208-13.

Nuanualsuwan, S., Thongtha, P., Kamolsiripichaiporn, S. and Subharat, S. (2008) UV inactivation and model of UV inactivation of foot-and-mouth disease viruses in suspension. International Journal of Food Microbiology, 127(1-2), 84-90.

Oliveira, A., Sillankorva, S., Quinta, R., Henriques, A., Sereno, R. and Azeredo, J. (2009) Isolation and characterization of bacteriophages for avian pathogenic E. coli strains. Journal of Applied Microbiology, 106(6), 1919-1927.

Rabbani, I. D., Radoja, U. N., Ray, S., Selim, A. and Weston, C. (2004) The Dynamics of bacteriophage T4 binding to Escherichia coli, Journal of Experimental Microbiology and Immunology (JEMI), 5, 61-64.

Rattanachaikunsopon, P. and Phumkhachorn, P. (2007) Bacteriophage PPST1 isolated from hospital wastewater, a potential therapeutic agent against drug resistant Salmonella enterica subsp. enterica serovar Typhi.in "Salmonella - Distribution, Adaptation, Control Measures and Molecular Technologies". Bassam A. Annous and Joshua B. Gurtler (Ed.) 2007. ISBN 978-953-51-0661-6.

Samhan, F. A. (2005) Coliphages as indicators and test organisms for assessment of hygienic safety of water, wastewater and liquid organic wastes, PhD Dissertation, University of Hohenheim, Germany. Verlag Grauer. Beuren and Stuttgart. ISBN 3861865033.

Snyder, A. B. (2012) Isolation and characterization of bacteriophage for the control of enterohemorrhagic Escherichia coli on fresh produce. PhD. Thesis, 2012 Ohio State University, USA.

Soliman, E. M., Mahdy, S. E. and Hassanin, A. I. (2013) Effect of different inactivators on the efficacy of Egyptian foot and mouth disease SAT2, Vaccine, 3(8), 392-399.

Srinivasan, P., Ramasamy, P., Brennan, G.P. and Hanna, R.E.B. (2007) Inhbitory effects of bacterophages on the growth of Vibrio sp. pathogens of shrimp in the Indian agaculture environment, Asian Journal of Animal and Veterinary Advances, 2,166-83.

Egypt. J. Microbiol. 51 (2016) 
Stanek, J. E. and Lacy, G. H. (1997) Development of a rapid coliphage detection assay. PhD. Thesis. Virginia Polytechnic Institute and State University, Blacksburg, VA., U.S.A.

Wang, A. and Lin, K. (2001) Effects of N-acetylglucosamine and $\alpha$-methylglucoside on bacteriophage T4 adsorption to Escherichia coli B23, Journal of Experimental Microbiology and Immunology (JEMI),1, 54-63.

Yang, H., Liang, L., Lin, S. and Jia, S. (2010) Isolation and characterization of a virulent bacteriophage AB1 of Acinetobacter baumannii. BMC Microbiology, 10(1), 131-137.

Zaritsky, A., Woldringh, C.L. and Mirelman, D. (1979) Constant peptidoglycan density in the sacculus of Escherichia coli B/r growing at different rates. FEBS, 98 (1),29-31.

(Received 19/10/2016; accepted 29/12/2016)

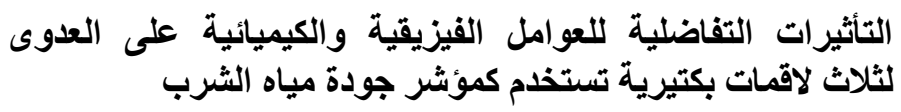

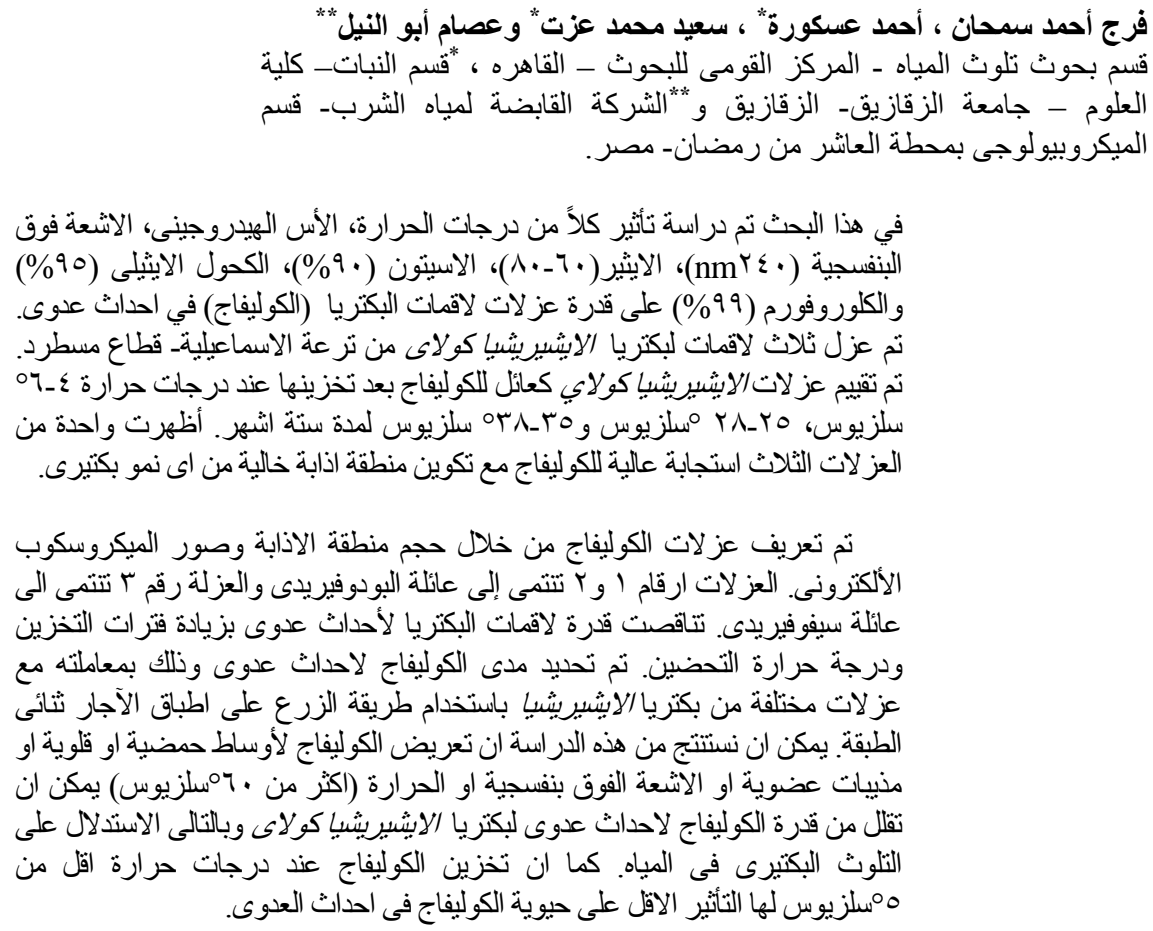

Egypt. J. Microbiol. 51 (2016) 